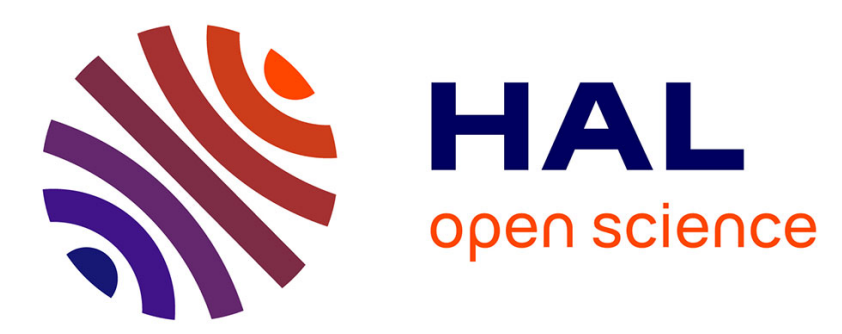

\title{
Temperature/emissivity separation using hyperspectral thermal infrared imagery and its potential for detecting the water content of plants
}

\author{
Hongyuan Huo, Zhao-Liang Li, Zefeng Xing
}

\section{- To cite this version:}

Hongyuan Huo, Zhao-Liang Li, Zefeng Xing. Temperature/emissivity separation using hyperspectral thermal infrared imagery and its potential for detecting the water content of plants. International Journal of Remote Sensing, 2019, 40 (5-6), pp.1672-1692. 10.1080/01431161.2018.1513668 . hal02377666

\section{HAL Id: hal-02377666 \\ https://hal.science/hal-02377666}

Submitted on 11 Dec 2020

HAL is a multi-disciplinary open access archive for the deposit and dissemination of scientific research documents, whether they are published or not. The documents may come from teaching and research institutions in France or abroad, or from public or private research centers.
L'archive ouverte pluridisciplinaire $\mathbf{H A L}$, est destinée au dépôt et à la diffusion de documents scientifiques de niveau recherche, publiés ou non, émanant des établissements d'enseignement et de recherche français ou étrangers, des laboratoires publics ou privés. 
Temperature/emissivity separation using Hyperspectral thermal infrared imagery and its potential for detecting the water content of plants

Hongyuan Huo ${ }^{1}$, Zhao-Liang Li $^{* 1,2}$, Zefeng Xing ${ }^{1}$

${ }^{1}$ Key Laboratory of Agricultural Remote Sensing, Ministry of Agriculture/Institute of Agricultural Resources and Regional Planning, Chinese Academy of Agricultural Sciences, Beijing, 100081, China

${ }^{2}$ ICube, CNRS, Université de Strasbourg, 300 Boulevard Sébastien Brant, CS10413, 67412 Illkirch, France 
Temperature/emissivity separation using Hyperspectral thermal infrared imagery and its potential for detecting the water content of plants

\begin{abstract}
Thermal infrared (TIR) remote sensing is among the most effective tools for retrieving land surface temperatures (LSTs) at different scales using remotely sensed data with different spatial resolutions. Significant advancements have recently been made in TIR sensor technology, and hyperspectral TIR images now provide an opportunity to separate temperatures and emissivities with high accuracy. In this study, an experiment is performed to retrieve temperatures and emissivities based on a hyperspectral TIR spectrometer, the HyperCam-LW (Long Wave), and show the potential of this instrument in detecting the water content variations, water deficiencies and health of plants. In this study, a temperature emissivity separation (TES) method based on spectral smoothness is used to retrieve the temperature and emissivity of wheat plants from hyperspectral TIR data. Based on the retrieved temperatures and emissivities, the variations in the emissivity from different wheat plants are observed, and the relationship between the emissivity dynamics and water content is analysed. A comparison of the temperature of different plants was performed, and the results clearly showed the canopy structure of the plants. Subsequently, the health of the wheat was analysed, and the results showed that for water-deficit plants, the emissivity increased in a consistent manner over all spectral bands while the spectral shape remained almost unchanged because the spectral emissivity is sensitive to water content variations in plants. In this paper, the results also demonstrated that it is possible and perhaps reasonable to attribute the overall increase in the emissivity of plants with water deficits to cavity effects resulting from biochemical and structural changes in the leaves caused by water deficits.
\end{abstract}

Keywords: Temperature/emissivity separation, Hyperspectral remote sensing, Thermal infrared, Leaf water content, Wheat

\title{
1. Introduction
}

All plants need an adequate supply of water to live and grow well (Boyer 1982). Thus, water in plants is important and plays a key role in vital processes, including respiration, photosynthesis and nutrient uptake (Bray 1997). To maintain these vital processes, 
plants absorb water from soil via their roots and then transport the water to their stems, leaves and even flowers (McCutchan 1992, F. et al. 2001). If an adequate water supply is not available, then plants will suffer water stress, which in turn affects their growth, reproduction and even survival (Hsiao 1973, Bradford 1982, Laio and Bray 1997, F. et al. 2001, Chaves 2009, Ni et al. 2015).

Water stress is a complex physiological response in plants subject to a limited availability of water (Hsiao 1973, 1976). Water-deficit stress, usually shortened to water stress or drought stress, is a phenotypic characteristic of dehydrated plants caused by a lack of water required to maintain cell concentrations at an acceptable and healthy level (Shinozaki 1997). Therefore, many problems will occur when plants suffer from water stress, such as harmful plant-water interactions that occur under such a situation. Thus, the early detection of water stress is important because water stress is the most critical abiotic stressor limiting plant growth, crop yields and food production quality (Tezara 1999, Siddique 2000, Lisar 2012, Leng et al. 2014, 2017).

The established methods for detecting water stress in plants in the field include using a pressure chamber to measure the xylem water potential of individual leaves in select target plants (Turner 1981, 1988), and measuring stomatal conductance with a porometer (Zhang 1989, Tardieu 1992, Choné 2001), in which the vapour concentration is measured by a porometer and a humidity sensor at two different locations within a defined path, the transpiration is determined, and then the stomatal conductance is directly calculated based on the known leaf transpiration. However, these two methods are time consuming and labour intensive, and they provide only point measurements, thus limiting the number of individuals that can be monitored to accurately characterize a field (Jones 2004, Jones 2009, Costa 2013). 
Reliable detection and prediction of water stress in plant is desirable for applications in agriculture, forestry, and land rehabilitation (Havaux and Lannoye 1983). Since the 1970s, remote and ground-based technologies have been developed to detect water stress, although most of these technologies were applied in laboratories because the instruments were bulky and heavy, which hampered their application in the field (Čatský 1969, Gausman 1977, Downton 1981). However, with the rapid development of sensor and satellite technology, remote sensing technologies have advanced significantly over the past three decades, and they have been increasingly used to determine water stress spatial patterns by many researchers (Yamasaki and Dillenburg 1999, Sims and Gamon 2002, Pu 2004, Stimson 2005, Campbell 2007). Hunt and Rock (1989) used near-and middle infrared spectral reflectance to detect water stress in oak, sweetgum and conifers. Gao (1995) developed a normalized difference water index as an estimate of vegetation water content with reflectance of $860 \mathrm{~nm}$ and $1240 \mathrm{~nm}$. Lichtenthaler et al. (1996) found that the reflectance from 670 to $680 \mathrm{~nm}$ was insensitive to chlorophyll a above $70 \mathrm{mg} \cdot \mathrm{m}^{-2}$ in tobacco leaves because of the saturated relationship between light absorption and pigment concentration. Foutry and Baret (1997) found that the reflectances at $1530 \mathrm{~nm}$ and $1720 \mathrm{~nm}$ are influenced by the liquid water in plant tissues and can be used to estimate the water content in vegetation. Champagne et al. (2003) developed a water index from the ratio between the reflectances at $900 \mathrm{~nm}$ and $970 \mathrm{~nm}$ and used it as an indicator of water content in plants. De Tar et al. (2006) found that the degree of water stress was strongly correlated to spectral bands from the visual and near infrared (VNIR) regions $(686 \mathrm{~nm}, 811 \mathrm{~nm}, 860$ $\mathrm{nm}$, and $850 \mathrm{~nm}$ ) based on multi- and hyperspectral datasets. Scientists have found that water stress could be determined based on wavelengths associated with the red edge (Peñuelas 1994, Dobrowski 2005, Clay 2006, Blackburn 2006, Campbell 2007, Eitel 
2011). Most of these studies are based on indexes of spectral channel algorithms within the VNIR spectral region. However, despite many successful case studies, determining and selecting suitable reflectance algorithms is difficult because of the influence of vegetation and site conditions on plant spectral reflectance.

Thermal infrared (TIR) remote sensing technology was also introduced to track water stress in the 1970s (Idso 1978, Jackson 1982). Many researchers have used handheld thermometers to detect the water stress in the laboratory, which then led to the development of normalized indexes based on leaf and air temperature, such as the crop water stress index (CWSI) (Gardner 1992, Moran 1994, Alderfasi 2001, Yuan 2004). A major reason for using the CWSI is its convenient calculations and potential for remote measurements, thus avoiding time-consuming techniques when used for water stress detection at the field or farm level (Yazar 1999, Testi 2008). However, many studies on temperature-based detection of water stress in plants are still using a handheld broadband TIR camera, and the temperatures are retrieved by only one channel under the assumption that emissivity is a constant. For example, the emissivity of vegetation is often set to 0.97 , although in nature, it is a variable parameter. Thus, the accuracy of temperature retrieval is limited by this assumption (Gontia 2008, Jones 2009, Ullah 2012, Bellvert 2014).

However, the recent advanced hyperspectral TIR imaging techniques provide an opportunity to retrieve more accurate temperatures based on hyperspectral TIR data, such as from the HyperCam-LW (Telops Inc., Quebec, Canada), Itres TASI-600, and Specim AisaOWL, which is the most recent hyperspectral TIR imaging system (Montembeault 2010, Lagueux 2012). This device can measure the emitted radiance of the target in many narrow spectral channels compared with the broadband handheld thermal porometer, and this instrument can perform stable temperature emissivity 
separation (TES) and accurate temperature retrieval (Adler-Golden 2014). In addition to the land surface temperatures, the hyperspectral TIR imager can accurately separate the emissivity of targets based on a TES. Many studies have been carried out over the topic of land surface temperature retrieval, and many methods for single or multi thermal infrared spectral channels remotely sensed images have also been developed including the mono-window method, split-window, and other multi spectral channel methods (Qin et al. 2001, Sorbino et al. 2004, Wan and Li 2008, Tang et al. 2008, Li et al. 2013a, 2013b). Regarding to the research of surface temperature retrieval from hyperspectral thermal infrared imagery, rarely previous literature focused on this due to lack of dataset. Until recent years, the hyperspectral thermal infrared instrument and the respective technology began to be used for commercial applications. Thus, the most methods for temperature/emissivity separation retrieval from hyperspectral thermal infrared images is mainly based on the iterative spectrally smooth temperature/emissivity separation (ISSTES) method proposed by Borel $(1998,2008)$.

Until recently, emissivity in vegetation has rarely been exploited in water stress studies based on the following three aspects: the spectral emissivity of plants has complex and low variations because of structural effects and physiological and biochemical processes; exact emissivity retrievals require accurate atmospheric corrections and TES methods; and the spectral and spatial resolutions as well as the signal to noise ratio of the most recent airborne and satellite TIR sensors are low (Gagnon 2014). Thus, only a few studies have focused on plant water stress in TIR using the spectral emissivity (Gerhards 2016, Rock 2016, Abdi 2017).

Based on the above discussion, we designed an experiment based on a hyperspectral TIR instrument, the HyperCam-LW TIR sensor, to retrieve the land surface temperature and emissivity. According to the temperature and emissivity results, 
we analysed emissivity variations with different water contents in plants and studied the potential of the TIR instrument to detect water deficits and the health condition of plants. Thus, we derived the following two objectives for this study based on the latest TIR hyperspectral imager instrument: retrieve an accurate spectral emissivity from a TES method and evaluate the ability and potential of spectral emissivity for detecting water stress in a controlled experiment.

\section{Hyperspectral Thermal Infrared Instrument Hyper-Cam}

The Hyper-Cam was designed from the ground up so that the controls and data acquisition are specifically optimized. The Telops Hyper-Cam is a lightweight and compact hyperspectral imaging instrument using Fourier Transfer Infrared (FTIR) spectral and temporal resolution (see Figure 1). The spectral resolution can be defined by the user and ranges from several channels to thousands of bands to fulfil the most demanding spectral characterizations. Two blackbodies are integrated into this instrument for radiance calibration. Thus, the sensor is capable of generating calibrated data in real time at the highest data rates, and the images acquired by the Hyper-Cam are radiance images.

The Hyper-Cam features a focal-plane array (FPA) detector containing $320 \times$ 256 pixels over a basic $6.4^{\circ} \times 5.1^{\circ}$ field-of-view (FOV), which is the maximum, although the FOV can be adjusted according to the specific application and corresponding request. The spectral resolution of the Hyper-Cam is between 0.25 and $150 \mathrm{~cm}^{-1}$ over the 8 to $12 \mu \mathrm{m}$ (Long Wave) spectral range. The Hyper-Cam offers high sensitivity for each pixel of the scene under observation, the single sweep NESR at 10 $\mu \mathrm{m}$ with a $128 \times 128$ window and a spectral resolution of $16 \mathrm{~cm}^{-1}$ is $24.1 \mathrm{nW} / \mathrm{cm}^{2} . \mathrm{sr}^{\mathrm{cm}} \mathrm{cm}^{-1}$. The spectral range of the sensor, which is defined as the spectral range where the NESR 
is better than 5 times the NESR at $10 \mu \mathrm{m}$, goes from 7.8 to $12 \mu \mathrm{m}$, besides, its lightweight nature makes it ideal for field operation.

\section{Materials and Methodology}

\subsection{Experiment}

In the period from October 23 to November 10, 2017, a field experiment to detect water variations and water deficits detection is conducted on wheat under controlled conditions next to the greenhouse of the Institute of Agricultural Resources and Area Planning of the Chinese Academy of Agricultural Sciences (CAAS: 3957'36'’ N, $\left.116^{\circ} 19^{\prime} 21^{\prime \prime} \mathrm{E}\right)$.

The start of the experiment was set at the beginning of growth of the wheat (the early stage of wheat growing), from the tillering to stem elongation or jointing stages. The water required in this stage accounts for nearly twenty percent of the total water required throughout through the growth stages of wheat, and a water deficit will produce considerable impacts on wheat growth. In this experiment, three potted wheat plants are evaluated only for the preliminary detection of water deficits. Over nearly 20 days, an external water supply (e.g., rainfall) was not available, although more than half of this time range had partial or heavy cloudy conditions. Thus, except for these days with poor weather and heavy clouds, good weather conditions with clear skies were observed for approximately 4 days. Before the measurements, the plants were moved outside to adapt to sunny conditions for at least one hour. The dataset was recorded at midday (from 10:30 to 14:00) under cloud-free conditions. In this experiment, a highly diffuse reference target (InfraGold, Labsphere Inc, North Sutton, USA) of known reflectance was used and centred in the scans to quantify down-welling radiance (DWR), and Hyper-Cam measurements were performed at the same time. The Fluke 
TIR thermometer was used to measure the surface temperature of the InfraGold, and the atmospheric DWR was calculated according to the Planck function. The atmospheric effects were removed based on the calculated down-welling radiance. The InfraGold was measured when each potted wheat was measured by the Hyper-Cam instrument. The time-domain reflectometry (TDR) was used to measure the soil volumetric moisture content to distinguish the soil moisture of different potted plants. Figure 1 clearly describes the experiment of the study.

\subsection{Measurement setup}

Hyperspectral thermal infrared imaging data were collected using HyperCamLW camera. The main preference of the Hyper-Cam instrument was set in this experiment, including the temperatures of two blackbodies (the cold blackbody and the hot blackbody), the spectral resolution, the FOV and the sensor observation height (see Figure 1). In this experiment, based on the suggestions of previous related literature (Adler-Golden et al. 2014, Gerhards et al. 2016), the temperature of the cold blackbody was set to the atmospheric temperature and the temperature of the hot blackbody was set to 15 degrees higher than the cold blackbody, during the experiment, the temperature of cold blackbody is often set to ambient temperature, and the temperature of hot blackbody is set to 15 degrees higher than ambient temperature. The spectral resolution was set to $2.5 \mathrm{~cm}^{-1}$ in the spectral domain from 865 to $1280 \mathrm{~cm}^{-1}$, resulting in 163 bands, and the FOV was set to $320 \times 256$ pixels. The height of the instrument was usually equal to the height of the tripod. To prevent disturbances by self-emission, the detector is cooled down to $65 \mathrm{~K}$. Besides, this spectrometer is equipped with a wideangle telescope and a $45^{\circ}$ titled gold-coated mirror, which allows a vertical view with a field of view. 


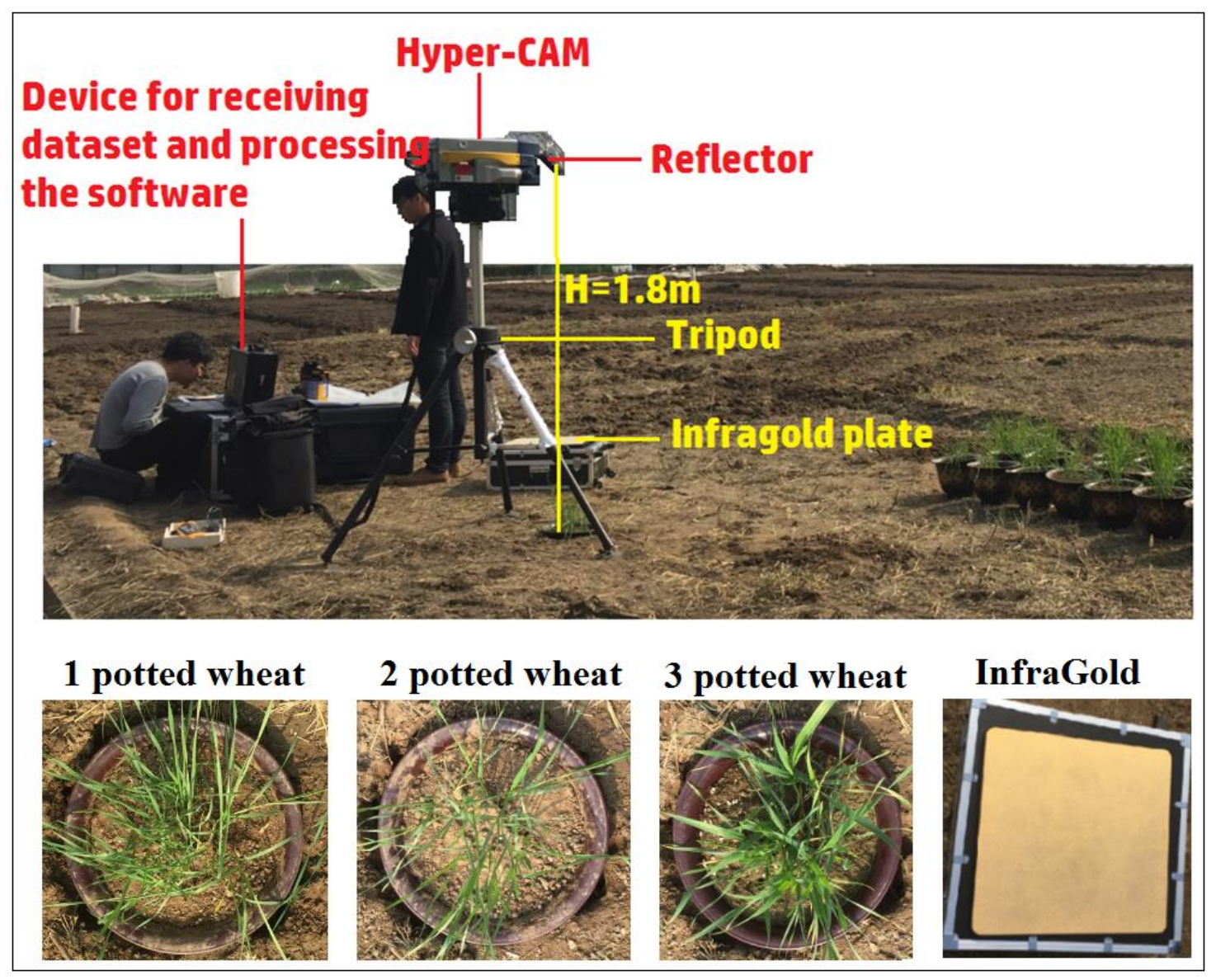

Figure 1. Experimental plant breeding of three potted wheat plants with a setup that included the Hyper-Cam on the tripod, Fluke TIR thermometer, and InfraGold.

\subsection{LST retrieval methods}

Over the past few decades, several methods are developed for hyperspectral remote sensing datasets and a number of error functions that are aimed at reducing retrieval errors. The ISSTES method is originally developed by Borel (1997) to infer the emissivity through varying the surface temperature in small steps based on a cost function. Comparing to the emissivity-based ISSTESS methods, Steve Adler-Golden (2001) further developed a TES method based on radiance. This paper used the radiance-based TES method to retrieve the land surface temperature and emissivity. To retrieve the surface temperature, the first step is to convert the raw interferograms into spectral radiance $\left(\mathrm{W} /\left(\mathrm{m}^{2} . \mathrm{sr}^{1} \cdot \mathrm{cm}^{-1}\right)\right)$. This step of radiometric calibration including a 
Fourier transformation and a two-point calibration is based on two internal blackbodies (cold blackbody and hot blackbody) with known temperatures and emissivities as well as bad pixel correction. All of these steps are performed using the Telops Reveal Calibrate software (made in Telops Ltd., Quebec City, Canada).

The next step is to retrieve the surface temperature using a TES method based on the spectral smoothness from spectral radiance datasets. The state of the art TES method allows for down-welling radiance (DWR) correction and is most suited for outside field measurements. The measurement of spectral radiance and the derivation of spectral emissivity and temperature in the field are processes that must be conducted carefully and thoughtfully. During the experiment, the Hyper-Cam-LW is used to acquire the hyperspectral TIR images. The iterative spectrally smooth temperature/emissivity separation (ISSTES) method is used, and the temperature and the emissivity are retrieved based on the down-welling radiance (DWR), which was measured using the InfraGold standard according to the smoothness of the ISSTES method. The main steps are as follows:

1) For temperature/emissivity separation, the long wave infrared (LWIR) spectral radiance measured at the sensor can be written as follows:

$$
L(\lambda)=\varepsilon(\lambda) B(\lambda, T) \tau(\lambda)+(1-\varepsilon(\lambda)) L^{\downarrow}(\lambda)+L^{\uparrow}
$$

where $\lambda$ is the wavelength, $B(\lambda, T)$ is the radiance of the blackbody at temperature $T$, $\tau(\lambda)$ is the transmission, $L^{\downarrow}(\lambda)$ is the down-welling radiance, and $L^{\uparrow}(\lambda)$ is the up-welling radiance. Solve equation (1) to determine the spectral emissivity $\varepsilon$ of the target yields at the ground:

$$
\varepsilon=\left(L(\lambda)-L^{\downarrow}(\lambda)\right) /\left(B\left(\lambda, T_{e s t}\right)-L^{\downarrow}(\lambda)\right)
$$

where $T_{\text {est }}$ is the estimated ground temperature, which is expressed as follows:

$$
T_{e s t}=B^{-1}\left(\lambda_{0},\left(L(\lambda)-\left(1-\varepsilon_{0}\right)\right) / \varepsilon_{0}\right)
$$


where $\lambda_{0}$ is a wavelength (typically $\lambda_{0}=10.1 \mu \mathrm{m}$ ) where the atmosphere is highly transmissive and $\varepsilon_{0}$ represents the emissivity and is typically set to 0.95 . Based on the down-welling radiance with the help of InfraGold (see Figure 2), equation (3) is used in equation (2) to determine an emissivity spectrum that shows atmospheric line features in the upper and lower curves.

2) The down-welling radiance is the energy incident on the InfraGold diffuse reflectance standard, and it can be calculated as follows:

$$
L^{\downarrow}(\lambda)=\left(L_{\text {InfraGold }}(\lambda)-\varepsilon_{\text {InfraGold }}(\lambda) L_{B B}\left(T_{\text {InfraGold }}, \lambda\right)\right) /\left(1-\varepsilon_{\text {InfraGold }}\right)
$$

where $\varepsilon_{\text {InfraGold }}$ is the flat spectral emissivity of InfraGold with a magnitude approximately equal to 0.04 . $L_{\text {InfraGold }}$ and $T_{\text {InfraGold }}$ can be directly measured.

3) Find the smoothest emissivity. The least squares radiance-based approach is used for temperature and emissivity retrieval in this method, and the best fitting temperature $T_{\mathrm{opt}}$ and emissivity is calculated based on a standard deviation $\sigma$ defined as follows:

$$
\begin{aligned}
& \sigma\left(T_{\text {opt }}, \bar{\varepsilon}_{\text {opt }}\right)=\sigma\left(L(\lambda)-L_{\text {fit }}\left(T_{\text {opt }}, \bar{\varepsilon}_{\text {opt }}\right)\right) \\
& =\sigma\left(L(\lambda)-\left[\bar{\varepsilon}_{\text {opt }} B\left(\lambda, T_{\text {opt }}\right) \tau+\left(1-\bar{\varepsilon}_{\text {opt }}\right) L^{\downarrow}(\lambda)+L^{\uparrow}\right]\right)=\min \\
& \quad \bar{\varepsilon}_{\text {opt }}=\left(\varepsilon_{n, m-1}+\varepsilon_{n, m}+\varepsilon_{n, m+1}\right) / 3, \mathrm{~m}=2, \ldots, \mathrm{M}-1
\end{aligned}
$$

where the three-point smoothed emissivity is denoted by $\bar{\varepsilon}_{\text {opt }}$, $\mathrm{n}$ is the number of spectral channels, and the $\mathrm{M}$ are the samples. This radiance-based TES method has the advantage that the spectral range can be extended to cover spectral regions where the atmospheric is not very transparent and that the fitting error itself can be compared directly to the sensor noise level (Borel, 2008).

Figure 2-5 is an example of retrieving surface temperature and optimal emissivity based on the above TES method. Figure 2 shows the reflectance of the InfraGold. Figure 3 is down-welling radiance of Nov. 1 2017, retrieved from the 
InfraGold plate with Eq. (4), and the Figure 4 is the illustration for estimating optimal emissivity based on Eq. (2) with a temperature offset from -10 K to $10 \mathrm{~K}$, as an illustration, the temperature offset from $-2 \mathrm{~K}$ to $2 \mathrm{~K}$ is taken as a case to show the iteration process for estimating the optimal emissivity. Figure 4 is the smoothness of the emissivity retrieved from TES with Eq. (5). In Figure 4, the smoothest emissivity can be calculated with the smallest smoothness shown in Figure 4 with red colour.

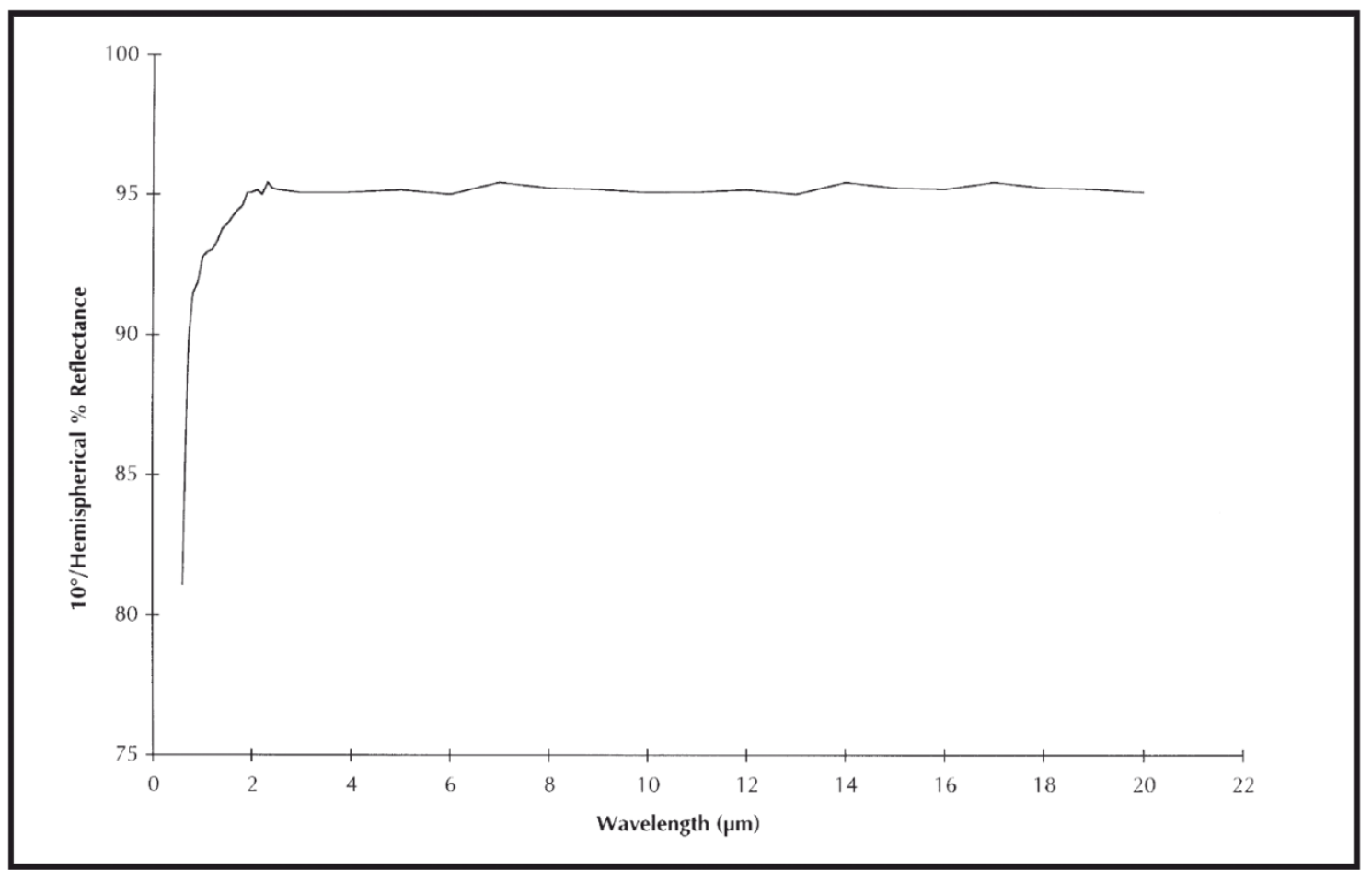

Figure 2. The hemispherical reflectance of InfraGold plate. 


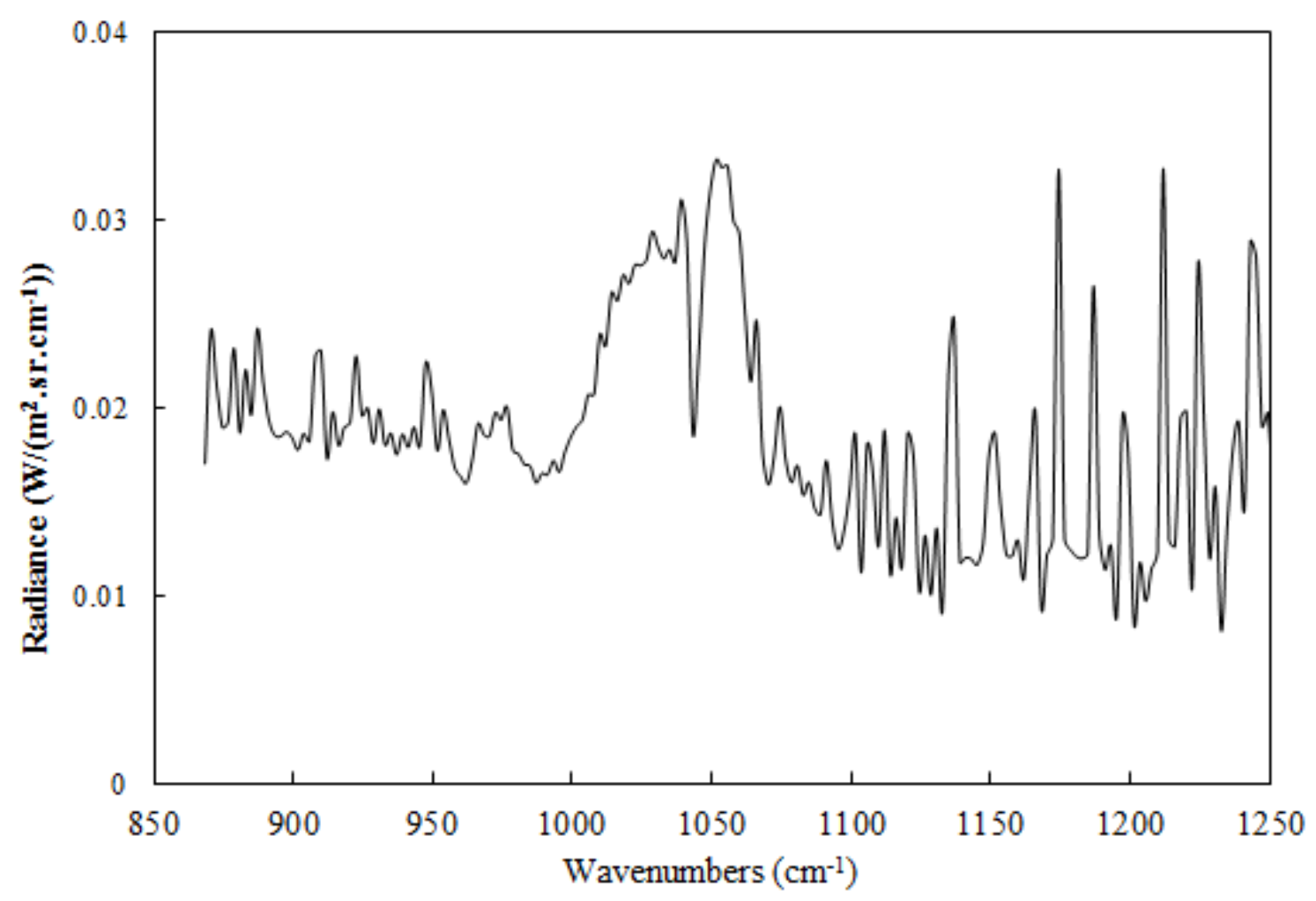

Figure 3. Down-welling radiance retrieved from the InfraGold plate on the 1st of November 2017.

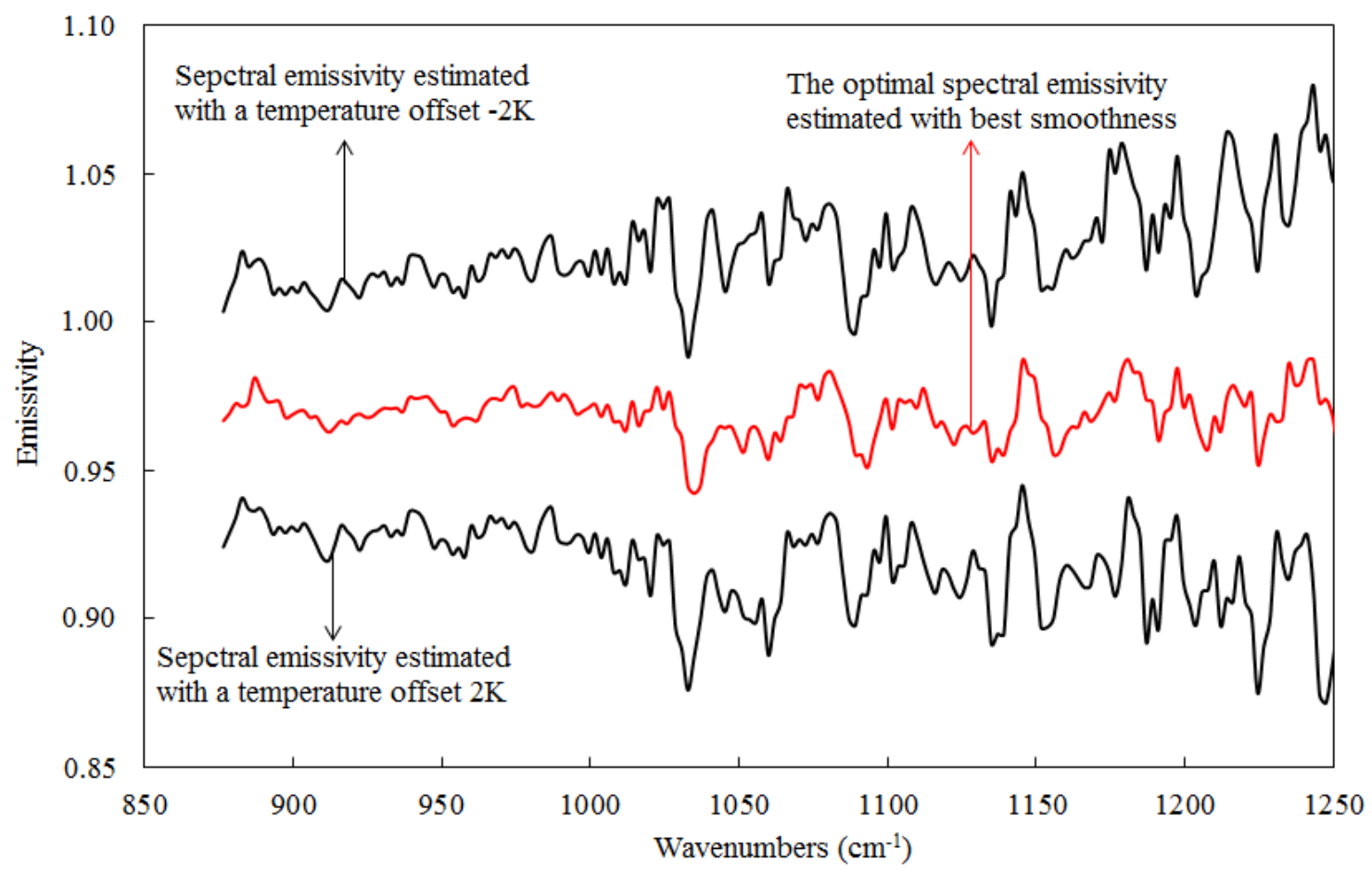

Figure 4. Illustration of iteration for estimating the optimal emissivity based on Eq. (2) using different LST offsets from $-10 \mathrm{~K}$ to $10 \mathrm{~K}$ for the potted wheat plants on the 1 st of 
November 2017, here, the temperature offset $-2 \mathrm{~K}$ to $2 \mathrm{~K}$ is taken as a case for illustration of iteration process.

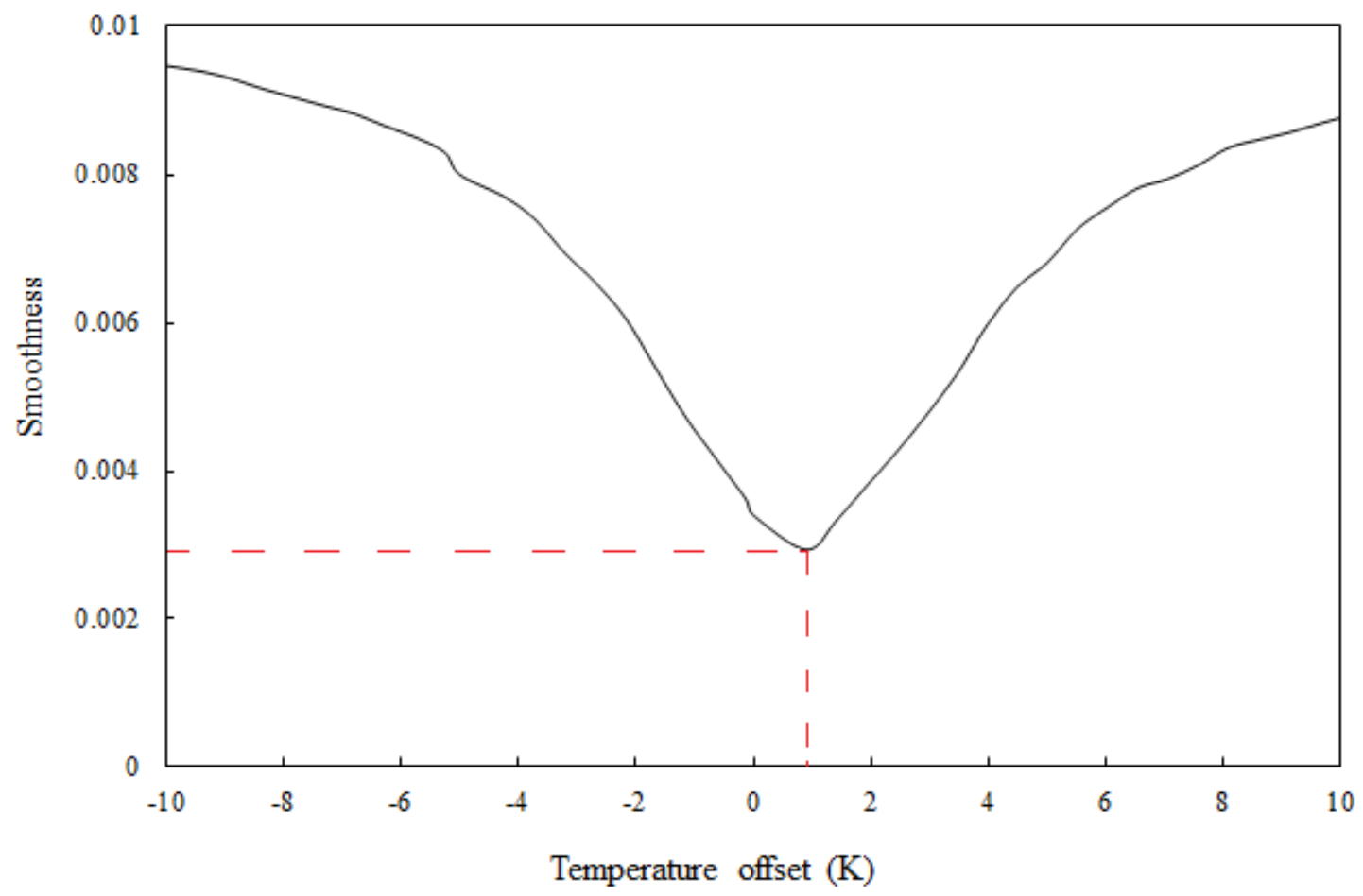

Figure 5. Smoothness of the emissivity as defined in Eq. (5).

\section{Results and Discussion}

\subsection{Sensitive analysis with the noise in the observation data.}

The single sweep NESR for the Hyper-Cam LW instrument was calculated for a $320 \times 256$ window centered in the FPA, at a spectral resolution of $2.5 \mathrm{~cm}^{-1}$. Figure 6 shows the average NESR at $10 \mu \mathrm{m}$ is $24.1 \mathrm{nW} / \mathrm{cm}^{2} \cdot \mathrm{sr}^{\cdot} \cdot \mathrm{cm}^{-1}$. As known to us, the influencing factors for LST retrieval accuracy are not only determined by the TES method itself, but also including the sensor noise. Here, we make the sensitive analysis of the TES method for the observation data with the instrument noise information by using the following equation

$$
\Delta \mathrm{LST}=L S T_{\text {without } N E S R}-L S T_{\text {with NESR }}
$$


where the $\mathrm{LST}_{\text {without NESR }}$ is the temperature retrieved directly by the observation data, and the LST $\mathrm{with}_{\text {NESR }}$ is the temperature retrieved by the observation data after adding the NESR information. The Figure 7 shows the error of temperature retrieval, the LST retrieval error is ranging from $-1.92 \sim 1.70 \mathrm{~K}$, and the corresponding RMSE is $0.52 \mathrm{~K}$.

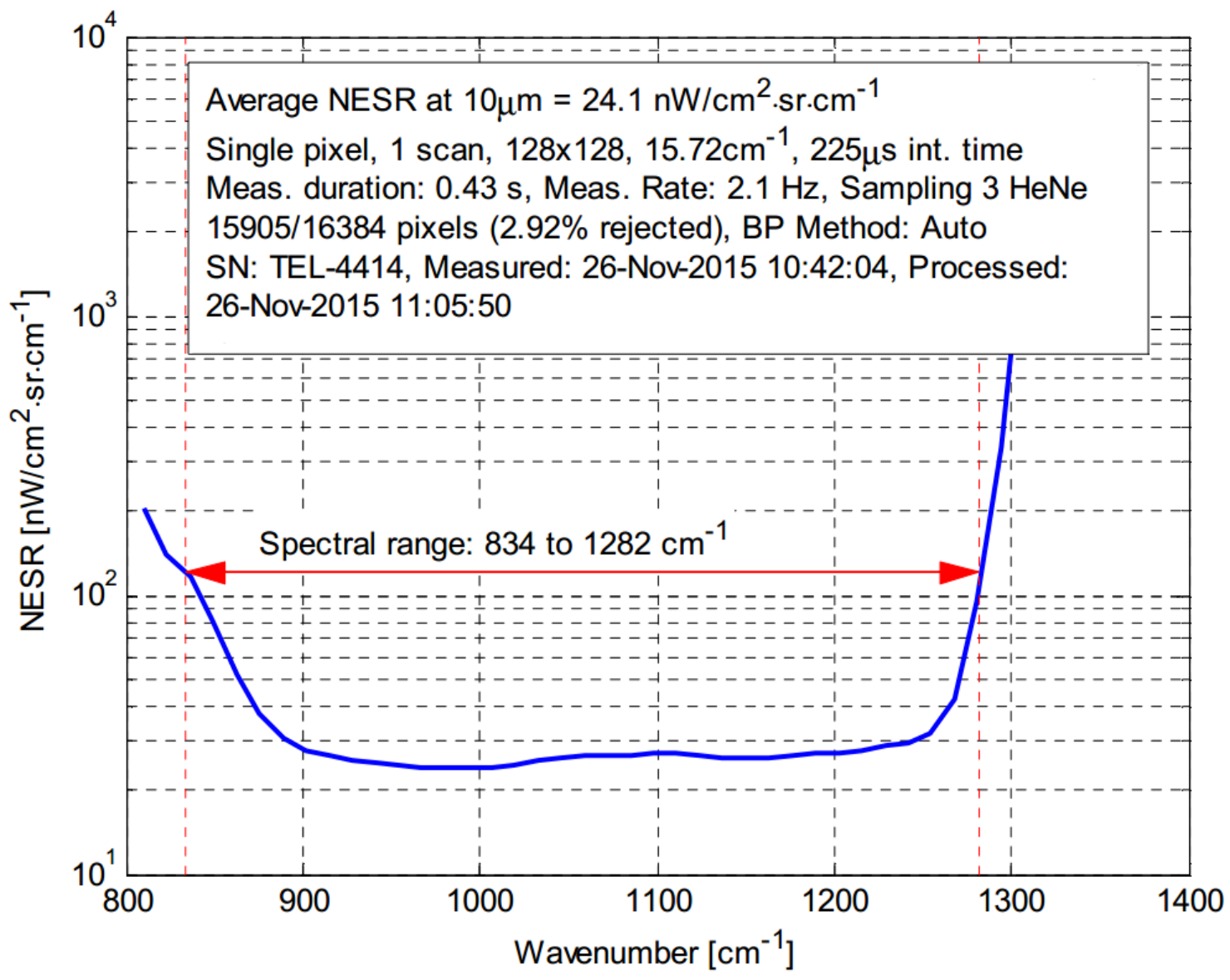

Figure 6 Spectral NESR measurement, averaged for all the good pixels 


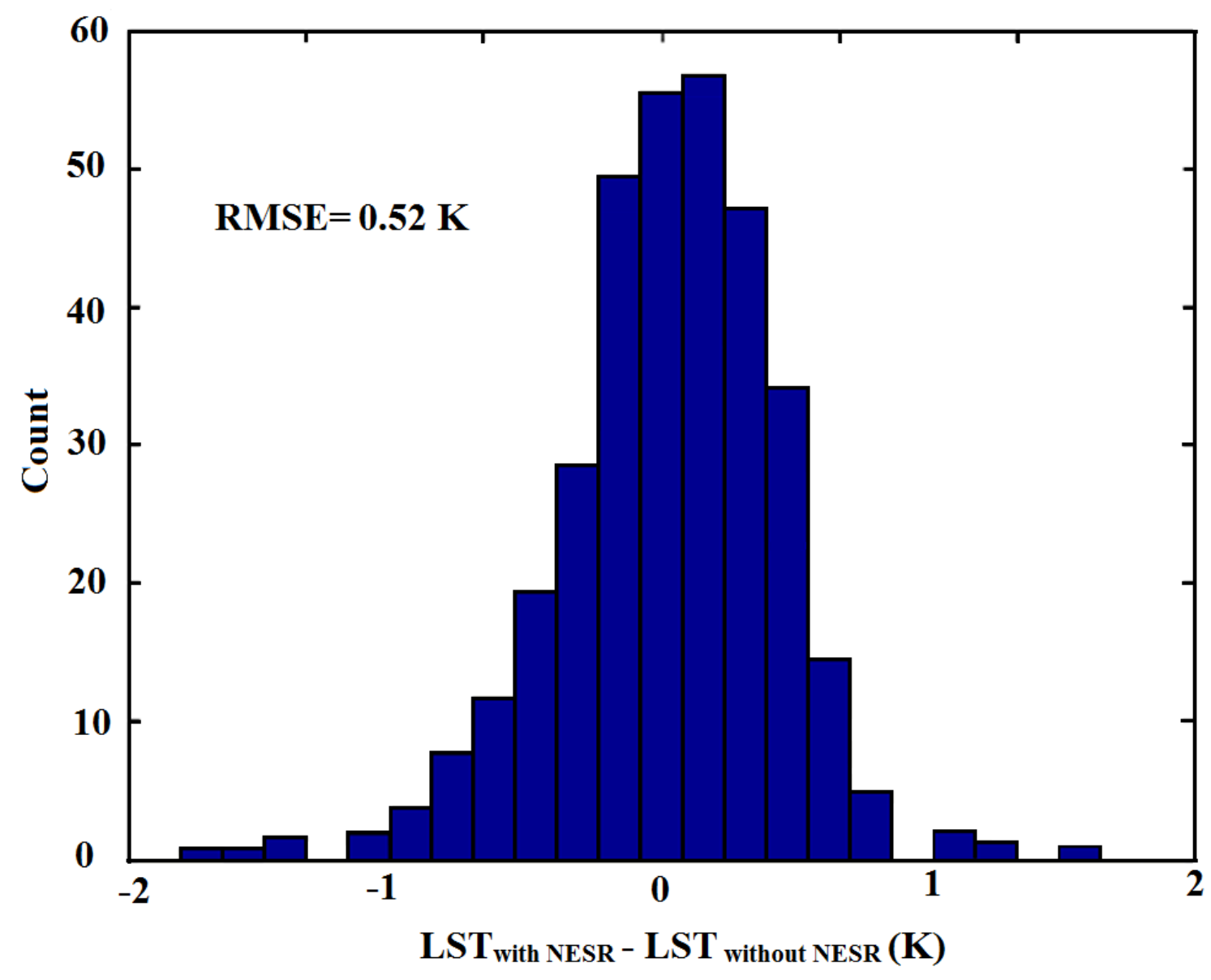

Figure 7 The histogram of the difference between the LST without NESR and the LST with NESR $(24.1 \mathrm{nW} / \mathrm{cm} 2 \cdot \mathrm{sr} \cdot \mathrm{cm}-1)$

\subsection{Temperature retrieval and the structure of wheat canopy}

Figure 8 shows an example of visual photos of the three different above-mentioned rows. From the Figure 8, the leaf area index ( LAI) and the soil moisture content (SMC) of these three potted wheat are different. Before and after starting the experiment, the water supply is not given for the wheat, the SMC for each potted wheat is measured by the TDR, and the specific SMC values of every potted wheat plant are listed in Table 1. Figure 9 and the recorded TDR data (see Table 1) show that health of the wheat under the water-deficit condition from the first experiment to the second experiment is not significantly affected; however, after the third experiment (including the third), a low 
SMC value is observed, and water loss is occurring in the leaves, and the leaves present a drying trend because of the significant loss of water content. In the fourth experiment, the leaves have lost a great amount of water content, the leaf structure is destroyed, and the plant's health is greatly affected, and these changes represent the general situation of the wheat plants.

Based on a TES method, the temperature is retrieved from the Hyper-Cam datasets. Determining the atmospheric conditions is important for retrieving accurate temperatures; thus, the InfraGold plate is used in this experiment. Figure 6 shows the surface temperatures of the first potted wheat plant of the above three rows retrieved from the TES method. This figure also shows that from the first measurement to the second measurement, the structure canopy and the colour differences between the two measurements can be clearly recognized under water-deficit conditions, although the plants are still healthy. However, in the third measurement, the considerable water loss in the leaves has left the structure canopy and colour difference vague and blurred; thus, the plant heath is significantly affected by a large water deficit. 


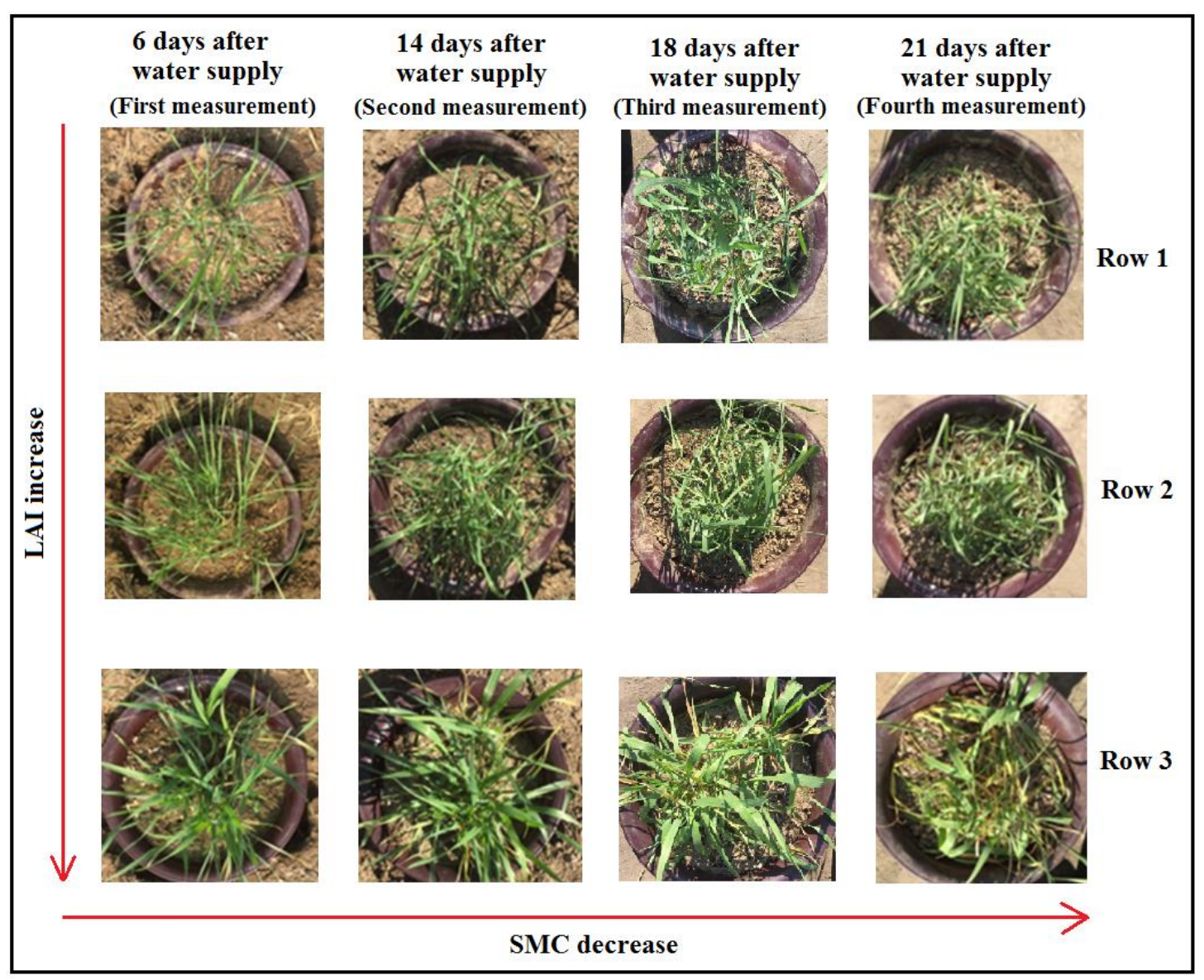

Figure 8. Potted wheat plants measured in this study.

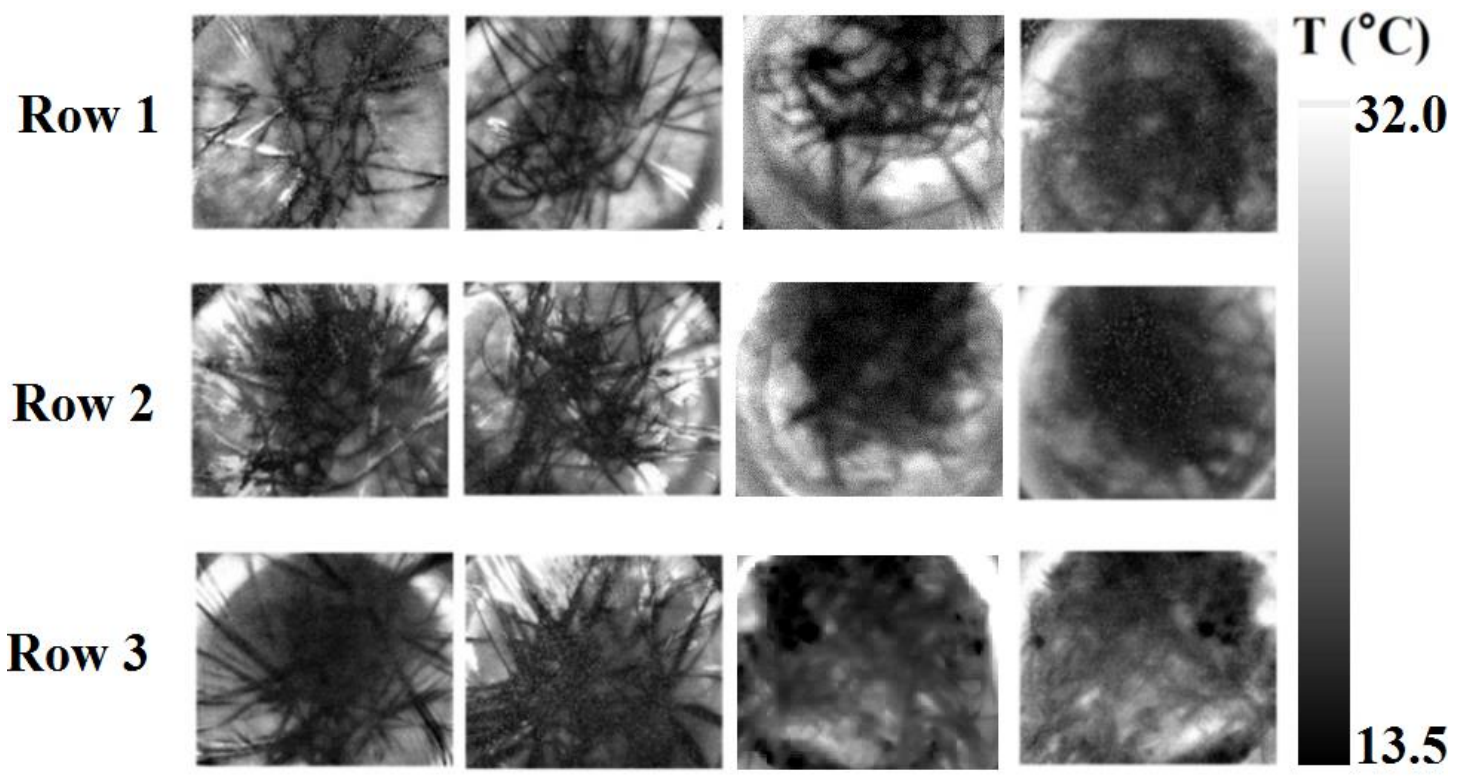

SMC=Soil Moisture Content

Figure 9. Temperature of three potted plants corresponding to Figure 5 retrieved from the TES method based on spectral smoothness. 
Table 1. Soil volumetric moisture content measured via TDR in this study $\left(\mathrm{cm}^{3} / \mathrm{cm}^{3}\right)$.

\begin{tabular}{ccccc}
\hline Plant & First & Second & Third & Fourth \\
& measurement & measurement & measurement & measurement \\
\hline Row 1 & 19.3 & 10.3 & 7.1 & 5.6 \\
Row 2 & 11.8 & 9.0 & 8.5 & 7.1 \\
Row 3 & 15.8 & 9.2 & 5.6 & 4.3 \\
\hline
\end{tabular}

\subsection{Comparative analysis of the emissivity retrieved from plants with different soil moisture contents}

In this experiment, the conductance in the leaves is not measured; thus, the water stress cannot be determined based on the conductance. However, the soil moisture is measured using a TDR instrument; thus, the basic conditions of the wheat can be estimated via the soil moisture (see Table 1). Regarding to the three potted wheat plants, the hyperspectral dataset is collected under different SMC conditions, and water is not supplied to the plants after the start of measurement. Table 1 shows that the SMC is very low, especially in the third and fourth measurements, and the health of the wheat plant is significantly affected, which can be seen from the temperature of the canopy structure of wheat (shown in Figure 9). During the process of collecting the datasets, the water supply is determined before the fourth measurement.

Based on the TES method as described in section 3, the emissivity of potted plants is retrieved. Figures 10-12 are the mean emissivities of these three potted wheat plants, which are all under water-deficit conditions. Before averaging the emissivity, the classification of these three potted wheats are done. Based on the classification results, the mean emissivity is averaged by a small moving window with $3 \times 3$ pixels. From the figures $10-12$, we can find that all spectra present a consistent shape with a prominent 
spectral feature at approximately $1050 \mathrm{~cm}^{-1}$. For example, weaker spectral features are also recognized at approximately $950 \mathrm{~cm}^{-1}, 1105 \mathrm{~cm}^{-1}, 1124 \mathrm{~cm}^{-1}$, or $1170 \mathrm{~cm}^{-1}$. The mean emissivity spectra show clear differences with different SMCs, especially in the fourth measurement. This measurement presented a low SMC (see Table 1), and the spectra are slightly less consistent but still prominent. The water deficit of wheat before the fourth measurement is serious and analysed in the above section via the temperature of the canopy structure of wheat. In these figures, the spectral emissivity is sensitive to the water deficit, and this variable can be developed into a sensitive tool to detect water variations and water stress in plants. The mean emissivity of every potted wheat in this paper is calculated based on the average of the respective emissivity of the canopy of wheat. Here, we also calculated the variance, standard deviation and p-values $(<0.0001)$. The calculated results are used to determine the mean emissivity for the water-deficit analysis.

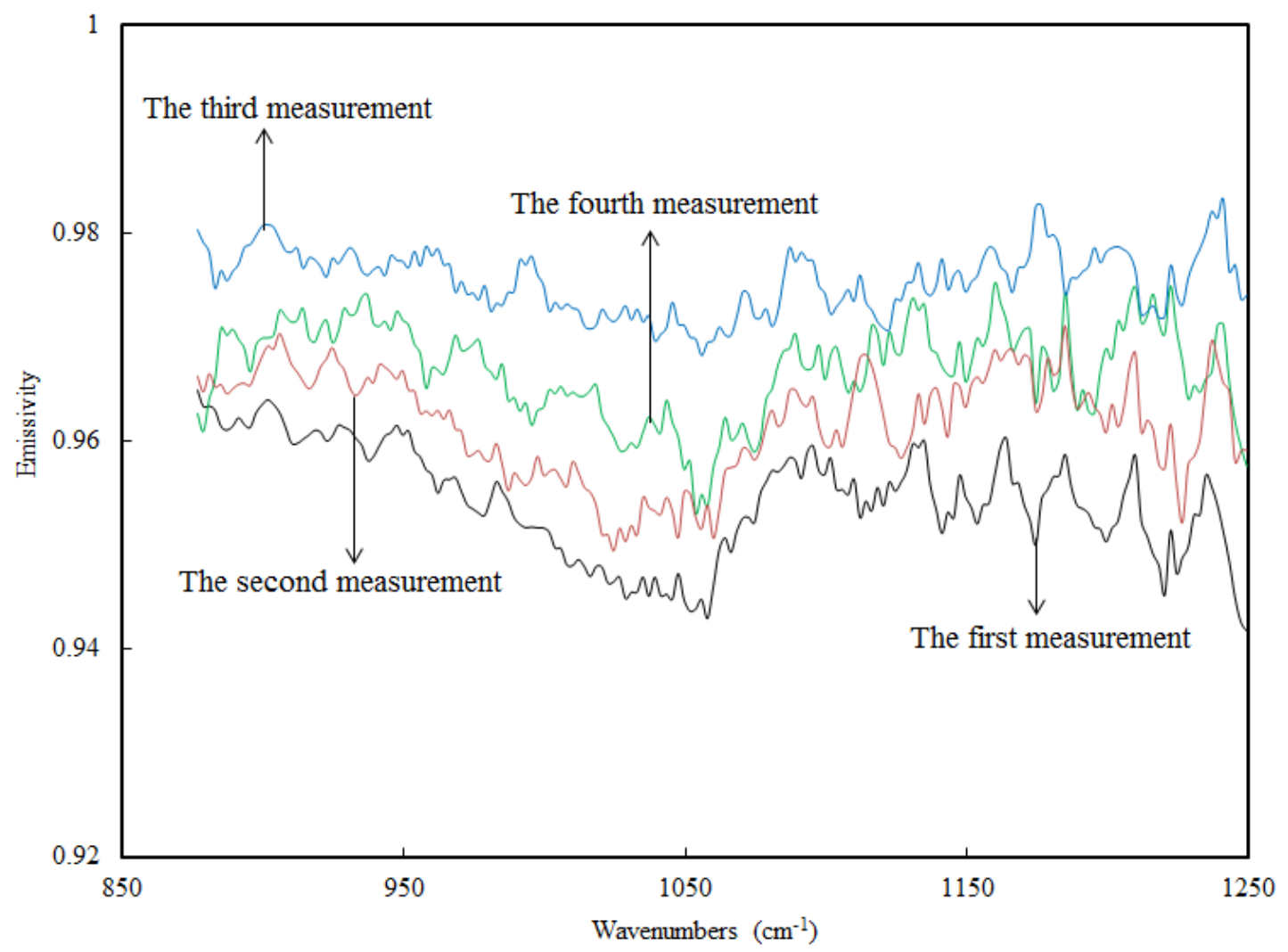


Figure 10. Mean emissivity spectra of the Row-1 potted wheat plant with different SMCs from the start date to the end of the experiment. Corresponding $p$-values of Mann-Whitney-U tests at a 5\% level of significance per wavenumber are grouped by significance.

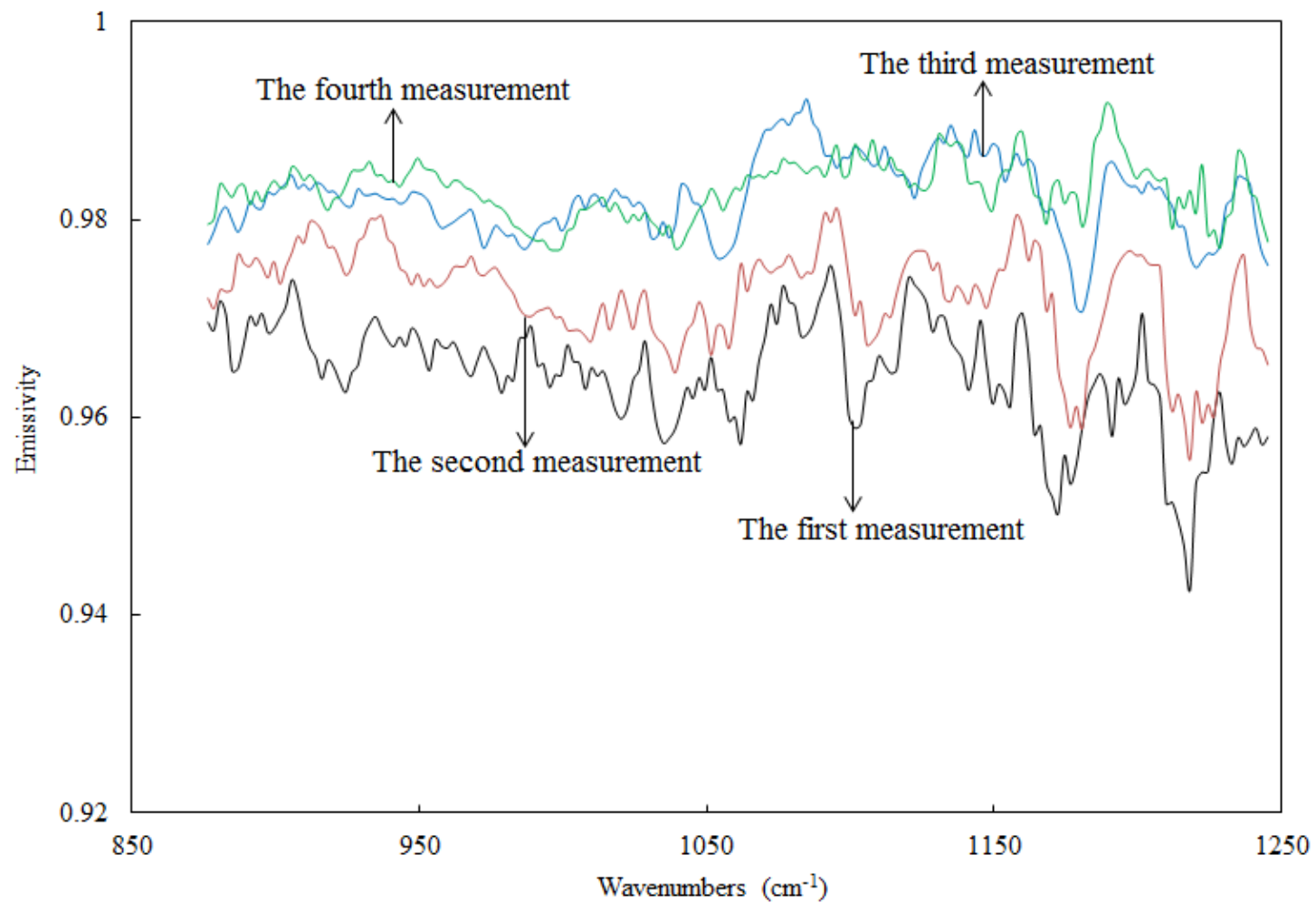

Figure 11. Mean emissivity spectra of the Row-2 potted wheat plant with different SMCs from the start date to the end of the experiment. Corresponding p-values of Mann-Whitney-U tests at a 5\% level of significance per wavenumber are grouped by significance. 


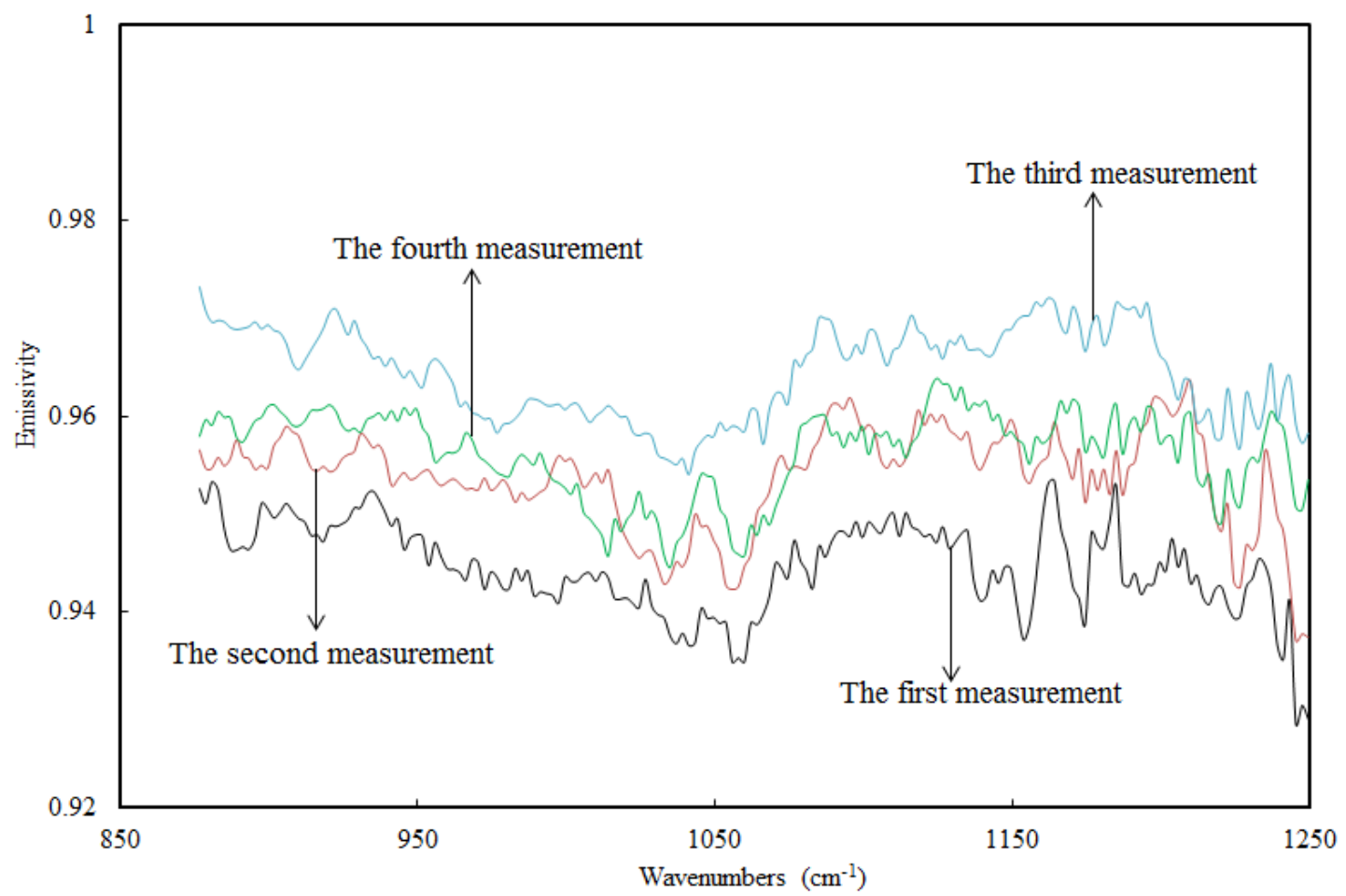

Figure 12. Mean emissivity spectra of the Row-3 potted wheat plant with different

SMCs from the start date to the end of the experiment. Corresponding $p$-values of Mann-Whitney-U tests at a 5\% level of significance per wavenumber are grouped by significance.

As analysed in the above section, the SMCs of the potted wheat plants are measured, and Table 1 and previous data indicate that the water deficit of the wheat leaves is serious, especially in the fourth measurement as shown by the LST results of the canopy structure of wheat. In the third measurement, the wheat leaves are becoming yellow and withered, and in the fourth experiment, the leaves become dry because of a great loss of water. Regarding Figure 10, the mean emissivity spectra of wheat presents an increase as the water deficit increases under variations of the SMC (see Table 1) in every potted wheat plant. However, in the fourth measurement, which indicates obvious and serious water-deficit conditions, the mean emissivity presents a limited decrease. Regarding Figure 11, a similar trend of variations in the mean emissivity spectra is found from the first to third measurement, whereas in the fourth measurement, Figure 
11 shows a clear decrease in the emissivity spectra because of the serious water deficit. The same situation and variation of emissivity is observed in Figure 12. This result was found for the different water-deficit conditions of wheat plants from the first to third measurement, where the emissivity increased in a consistent manner over all spectral bands and the spectral shape remained similar.

Similar results in other plants, such as potatoes and rhododendron, were also observed by Buitrago (2016) and Max Gerhards (2016), and these authors also observed a similar increase of emissivity for water-stressed plants and related this increase to cavity effects, which resulted in an increase of cuticle thickness. Additionally, this experiment also shows that the emissivity spectra decrease for significantly stressed wheat plants as demonstrated by the fourth experiment on wheat, which showed a considerable loss of water and a decreasing trend towards the spectra of dry grass. This trend may be related to changes in the internal structure, physical and biochemical properties of the plant, and normal photosynthesis processes.

\section{Conclusion}

In this paper, hyperspectral TIR datasets are used to determine the emissivity based on the water content of plants and the relationship between emissivity and water content. Field experiments are conducted under clear sky conditions, and three potted wheat plants are used as the examples. In this study, we separated the surface temperature and emissivity in the hyperspectral TIR datasets based on the Telops Hyper-Cam LW instrument by using a TES method. Based on the temperature and emissivity results retrieved from the remotely sensed datasets, the variations of emissivity from different wheat plants are observed, and the relationship between the water-deficit conditions and emissivity dynamics is analysed. The potted wheat temperatures on the different days under a water deficit are compared, the changes in the canopy structure of plants can be 
observed via the surface temperatures, and the corresponding heath of the plant may be inferred.

The main conclusions based on this experiment are as follows: in the first, the hyperspectral thermal infrared instrument is proved to be an effective tool for detecting the water content dynamics of the leaves, and it also can be also used to monitor the health for crops; secondly, the temperature for different plants under water-deficit conditions was compared to evaluate the canopy structure of the plants and determine the health of the plant; and thirdly, emissivity was sensitive to water variations and water deficits because it presented notable changes, and the spectral emissivity showed an overall increase as the water deficit increased, and this phenomenon was demonstrated by the wheat plants under water-deficit conditions; at last, the spectral features of wheat within the TIR spectral region were also addressed. Moreover, this study found that the spectral features, which cannot be allocated to structural characteristics or biochemical compounds because of the lack of available reference measurements (e.g., cuticle thickness), are similar to previous results obtained by other researchers. We also indicted that the cause for the overall increase in plant emissivity under a water-deficit condition may be cavity effects resulting from biochemical and structural changes in the leaves caused by the water deficit.

General studies of water variations and water deficits of plants based on a hyperspectral remotely sensed dataset may be insufficient because of climate conditions and short experimental periods. However, VNIR and short-wave infrared spectral region reflectance measurements are not introduced in this study, and reflectance-based methods are not used here. Thus, further investigations should be conducted with a longer period of observation and additional remote sensing tools should be developed in the future. The potential application of hyperspectral TIR imaging techniques in 
precision agriculture and parameters related to retrieval also warrant further investigation.

\section{Acknowledgements}

This research was supported by grants from the National Natural Science Foundation of China (41701425), the China Postdoctoral Science Foundation (2016M601181), the National Natural Science Foundation of China (41231170), and the National Key Basic Research Program (2013CB733402).

\section{Disclosure statement}

No potential conflicts of interest were reported by the authors.

\section{References}

Abdi, G., F. Samadzadegan and P., Reinartz. 2017. "Spectral-spatial feature learning for hyperspectral imagery classification using deep stacked sparse autoencoder." Journal of Applied Remote Sensing 11(4):04260401-042604015. doi:10.1117/1.JRS.11.042604

Alderfasi, A.A. and D.C., Nielsen. 2001. "Use of crop water stress index for monitoring water status and scheduling irrigation in wheat." Agricultural water management 47(1): 69-75. doi:10.1016/S0378-3774(00)00096-2

Adler-Golden, S., P., Conforti, M.A., Gagnon, P., Tremblay and M., Chamberland 2014. "Remote sensing of surface emissivity with the Telops Hyper-Cam." In Proceedings of the IEEE Workshop on Hyperspectral Image and Signal Processing: Evolution in Remote Sensing (WHISPERS), 1-4. Lausanne, Switzerland.

doi:10.1109/WHISPERS.2014.8077616

Bellvert, J., P.J., Zarco-Tejada, J., Girona and E., Fereres. 2014. "Mapping crop water stress index in a 'Pinot-noir'vineyard: comparing ground measurements with 
thermal remote sensing imagery from an unmanned aerial vehicle." Precision agriculture 15(4): 361-376. doi:10.1007/s11119-013-9334-5

Blackburn, G.A., 2006. "Hyperspectral remote sensing of plant pigments.” Journal of experimental botany 58(4): 855-867.doi:10.1093/jxb/erl123

Borel, C. C. Surface emissivity and temperature retrieval for a hyperspectral sensor. 1998. In IEEE International Proceedings of Geoscience and Remote Sensing Symposium, 546-549. Seattle, WA, USA. doi:10.1109/IGARSS.1998.702966

Borel, C. C. 2008. Error analysis for a temperature and emissivity retrieval algorithm for hyperspectral imaging data. International Journal of Remote Sensing 29(1718):5029-5045. doi:10.1080/01431160802036540

Boyer, J.S., 1982. "Plant productivity and environment.” Science 218(4571):443-448. doi:10.1126/science.218.4571.443

Bradford, K.J. and T.C., Hsiao. 1982. "Physiological responses to moderate water stress.” In Physiological plant ecology II 263-324. Berlin Germany: Springer Heidelberg. doi:10.1007/978-3-642-68150-9_10

Bray, E.A., 1997. "Plant responses to water deficit." Trends in plant science 2(2):48-54. doi:10.1016/S1360-1385(97)82562-9

Buitrago, M. F., T. A., Groen, C. A., Hecker and A. K., Skidmore. 2016. "Changes in thermal infrared spectra of plants caused by temperature and water stress". ISPRS Journal of Photogrammetry and Remote Sensing 111(2016): 22-31. doi:10.1016/j.isprsjprs.2015.11.003

Campbell, P.K.E., E.M., Middleton, J.E., McMurtrey and E.W., Chappelle 2007. "Assessment of vegetation stress using reflectance or fluorescence measurements." Journal of environmental quality 36(3):832-845. doi:10.2134/jeq2005.0396 
Čatský, J., 1969. “Temperature effects in the measurement of water saturation deficit (relative water content) in tobacco and kale.” Biologia Plantarum 11(5):381-383. doi:10.1007/BF02921404

Chamberland, M. 2012. "Airborne infrared hyperspectral imager for intelligence, surveillance and reconnaissance applications." In Processdings of Airborne Intelligence, Surveillance, Reconnaissance (ISR) Systems and Applications IX, 854226-854226. Edinburgh, United Kingdom. doi:10.1117/12.974520

Champagne, C.M., K., Staenz, A., Bannari, H., McNairn and J.C., Deguise. 2003. "Validation of a hyperspectral curve-fitting model for the estimation of plant water content of agricultural canopies." Remote Sensing of Environment 87(2):148-160. doi:10.1016/S0034-4257(03)00137-8

Chaves, M.M., J., Flexas and C., Pinheiro. 2009. "Photosynthesis under drought and salt stress: regulation mechanisms from whole plant to cell." Annals of botany 103(4):551-560. doi:10.1093/aob/mcn125

Choné, X., C., Van Leeuwen, D. Dubourdieu and J.P., Gaudillère. 2001. “Stem water potential is a sensitive indicator of grapevine water status." Annals of botany 87(4):477-483. doi:10.1006/anbo.2000.1361

Clay, D.E., K.I., Kim, J., Chang, S.A., Clay and K., Dalsted. 2006. "Characterizing water and nitrogen stress in corn using remote sensing." Agronomy Journal 98(3): 579-587. doi:10.2134/agronj2005.0204

Costa, J.M., O.M., Grant and M.M., Chaves. 2013. "Thermography to explore plantenvironment interactions." Journal of Experimental Botany 64(13):3937-3949. doi:10.1093/jxb/ert029 
DeTar, W.R., J.V., Penner and H.A., Funk. 2006. "Airborne remote sensing to detect plant water stress in full canopy cotton." Transactions of the ASABE 49(3):655-665. doi:10.13031/2013.20485

Dobrowski, S.Z., J.C., Pushnik, P.J., Zarco-Tejada and S.L., Ustin. 2005. “Simple reflectance indices track heat and water stress-induced changes in steady-state chlorophyll fluorescence at the canopy scale." Remote Sensing of Environment 97(3):403-414. doi:10.1016/j.rse.2005.05.006

Downton, W.J.S., D.C., Fork, and P.A., Armond. 1981. "Chlorophyll a fluorescence transient as an indicator of water potential of leaves." Plant Science Letters 20(3): 191-194. doi:10.1016/0304-4211(81)90261-3

Eitel, J.U., L.A., Vierling, M.E., Litvak, D.S., Long, U., Schulthess, A.A., Ager, D.J., Krofcheck and L., Stoscheck. 2011. "Broadband, red-edge information from satellites improves early stress detection in a New Mexico conifer woodland." Remote Sensing of Environment 115(12):3640-3646. doi:10.1016/j.rse.2011.09.002

Faurtyot, T. and F., Baret. 1997. "Vegetation water and dry matter contents estimated from top-of-the-atmosphere reflectance data: a simulation study." Remote Sensing of Environment 61(1): 34-45. doi:10.1016/S0034-4257(96)00238-6

Gagnon, M.A., P., S., Tremblay, V., Savary, P., Farley, Lagueux and M., Chamberland. 2014. "Airborne thermal hyperspectral imaging of urban and rural areas." In IEEE International Proceedings of Geoscience and Remote Sensing Symposium, 13691372. Quebec, Canada. doi:10.1109/IGARSS.2014.6946689

Gao, B.C. 1995. "Normalized difference water index for remote sensing of vegetation liquid water from space." In SPIE's Symposium of International Society for Optics and Photonics on OE/Aerospace Sensing and Dual Use Photonics, 225-236.

Orlando, FL, United States. doi:10.1117/12.210877 
Gardner, B.R., D.C., Nielsen and C.C., Shock. 1992. "Infrared thermometry and the crop water stress index. I. History, theory, and baselines." Journal of production agriculture 5(4): 462-466. doi:10.2134/jpa1992.0462

Gerhards, M., G., Rock, M., Schlerf, T., Udelhoven and W., Werner. 2015. "Water stress detection using hyperspectral thermal infrared remote sensing." In Proceedings of the IEEE Workshop on Hyperspectral Image and Signal Processing: Evolution in Remote Sensing (WHISPERS), 1-4. Tokyo, Japan. doi:10.1109/WHISPERS.2015.8075366

Gausman, H.W. 1977. "Reflectance of leaf components.” Remote sensing of Environment 6(1): 1-9. doi:10.1016/0034-4257(77)90015-3

Gerhards, M., G., Rock, M., Schlerf and T., Udelhoven. 2016. "Water stress detection in potato plants using leaf temperature, emissivity, and reflectance.” International Journal of Applied Earth Observation and Geoinformation 53(2016): 27-39. doi:10.1016/j.jag.2016.08.004

Gontia, N.K. and K.N., Tiwari. 2008. "Development of crop water stress index of wheat crop for scheduling irrigation using infrared thermometry." Agricultural water management 95(10): 1144-1152. doi:10.1016/j.agwat.2008.04.017

Havaux, M. and R., Lannoye. 1983. "Chlorophyll fluorescence induction: a sensitive indicator of water stress in maize plants." Irrigation Science 4(2): 147-151. doi:10.1007/BF00273382

Hsiao, T.C. 1973. "Plant responses to water stress." Annual review of plant physiology 24(1): 519-570. doi:10.1146/annurev.pp.24.060173.002511

Hsiao, T.C., E., Fereres, E., Acevedo and D.W., Henderson. 1976. "Water stress and dynamics of growth and yield of crop plants.” In Water and plant life, 281-305. Berlin, Germany: Springer Heidelberg. doi:10.1007/978-3-642-66429-8_18 
Hunt, E.R. and B.N., Rock. 1989. "Detection of changes in leaf water content using near-and middle-infrared reflectances." Remote sensing of environment 30(1): 4354. doi:10.1016/0034-4257(89)90046-1

Idso, S.B., R.D., Jackson and R.J., Reginato. 1978. "Extending the" degree day" concept of plant phenological development to include water stress effects." Ecology 59(3): 431-433. doi:10.2307/1936570

Jackson, R.D., 1982. "Canopy temperature and crop water stress.” Advances in irrigation 1(1982): 43-85. doi:10.1016/B978-0-12-024301-3.50009-5

Jones, H.G., 2004. "Irrigation scheduling: advantages and pitfalls of plant-based methods." Journal of experimental botany 55(407): 2427-2436. doi:10.1093/jxb/erh213

Jones, H.G., R., Serraj, B.R., Loveys, L., Xiong, A., Wheaton and A.H., Price. 2009. "Thermal infrared imaging of crop canopies for the remote diagnosis and quantification of plant responses to water stress in the field." Functional Plant Biology 36(11): 978-989. doi:10.1071/FP09123

Lagueux, P., E., Puckrin, C.S., Turcotte, M.A., Gagnon, J., Bastedo, V., Farley, G., Rock, M., Gerhards, M., Schlerf, C., Hecker and T., Udelhoven. 2016. "Plant species discrimination using emissive thermal infrared imaging spectroscopy." International Journal of Applied Earth Observation and Geoinformation 53(2016): 16-26. doi:10.1016/j.jag.2016.08.005

Laio, F., A., Porporato, L. Ridolfi and I., Rodriguez-Iturbe. 2001. "Plants in watercontrolled ecosystems: active role in hydrologic processes and response to water stress: II. Probabilistic soil moisture dynamics." Advances in Water Resources 24(7): 707-723. 
Leng, P., X. Song, Z.-L. Li, J. Ma, F. Zhou, and S. Li. 2014. "Bare Surface Soil Moisture Retrieval from the Synergistic Use of Optical and Thermal Infrared Data." International Journal of Remote Sensing 35: 988-1003. doi:10.1080/01431161.2013.875237.

Leng, P., Z.-L. Li, S. Duan, M. Gao, and H. Huo. 2017. "A Practical Approach for Deriving All-weather Soil Moisture Content Using Combined Satellite and Meteorological Data." ISPRS Journal of Photogrammetry and Remote Sensing 131: 40-51. doi:10.1016/j.isprsjprs.2017.07.013.

Li Z.-L., H. Wu, N. Wang, S. Qiu, J.A. Sobrino, Z. Wan, B.-H. Tang, and G.J. Yan, (2013), Land surface emissivity retrieval from satellite data. International Journal of Remote Sensing 34(9-10): 3084-3127. doi:10.1080/01431161.2012.716540.

Li Z.-L., B.-H. Tang, H. Wu, H. Ren, G.J. Yan, Z. Wan, I.F. Trigo and J. Sobrino, (2013), Satellite-derived land surface temperature: Current status and perspectives. Remote Sensing of Environment. 131: 14-37. doi:10.1016/j.rse.2012.12.008 Lichtenthaler, H.K., C., Buschmann, U. Rinderle and G., Schmuck. 1986. “Application of chlorophyll fluorescence in ecophysiology." Radiation and environmental biophysics 25(4): 297-308. doi:10.1007/BF01214643

Lisar, S.Y., R., Motafakkerazad, M.M., Hossain and I.M., Rahman. 2012. "Water stress in plants: causes, effects and responses." In Water stresss, 1-15. Rijeka, CroatiaEuropean Union: InTechOpen. doi:10.5772/1419

McCutchan, H. and K.A., Shackel. 1992. "Stem-water potential as a sensitive indicator of water stress in prune trees." Journal of the American Society for Horticultural Science 117(4): 607-611.

Montembeault, Y., P., V., Lagueux, Farley, A. Villemaire and K.C., Gross. 2002. "Hyper-Cam: Hyperspectral IR imaging applications in defence innovative 
research." In Proceedings of the IEEE Workshop on Hyperspectral Image and Signal Processing: Evolution in Remote Sensing (WHISPERS), 1-4. Reykjavik, Iceland. doi:10.1109/WHISPERS.2010.5594890

Moran, M.S., T.R., Clarke, Y. Inoue and A., Vidal. 1994. "Estimating crop water deficit using the relation between surface-air temperature and spectral vegetation index." Remote sensing of environment 49(3): 246-263. doi:10.1016/0034-4257(94)90020-5

Ni, Z., Z., Liu, H., Huo, Z.-L., Li; F., Nerry, Q., Wang and X., Li. 2015. “Early Water Stress Detection Using Leaf-Level Measurements of Chlorophyll Fluorescence and Temperature Data.” Remote Sensing 7(3): 3232-3249. doi:10.3390/rs70303232

Peñuelas, J., J.A., Gamon, A.L., Fredeen, J. Merino and C.B., Field. 1994. "Reflectance indices associated with physiological changes in nitrogen-and water-limited sunflower leaves." Remote sensing of Environment 48(2): 135-146. doi:10.1016/0034-4257(94)90136-8

Pu, R., S., Ge, N.M. Kelly and P., Gong. 2003. "Spectral absorption features as indicators of water status in coast live oak (Quercus agrifolia) leaves.” International Journal of Remote Sensing 24(9): 1799-1810. doi:10.1080/01431160210155965

Qin, Z., Karnieli, A., \& Berliner, P. 2001. “A mono-window algorithm for retrieving land surface temperature from Landsat TM data and its application to the IsraelEgypt border region.” International journal of remote sensing, 22(18): 3719-3746. doi:10.1080/01431160010006971

Shinozaki, K. and K., Yamaguchi-Shinozaki. 1997. "Gene expression and signal transduction in water-stress response.” Plant physiology 115(2): 327-334.

Siddique, M.R.B., A. Hamid and M.S., Islam. 2000. "Drought stress effects on water relations of wheat." Botanical Bulletin of Academia Sinica, 41(2000): 35-39. 
Sims, D.A. and J.A., Gamon 2002. "Relationships between leaf pigment content and spectral reflectance across a wide range of species, leaf structures and developmental stages." Remote sensing of environment 81(2): 337-354. doi:10.1016/S0034-4257(02)00010-X

Sobrino, J. A., Jiménez-Muñoz, J. C., \& Paolini, L. 2004. “Land surface temperature retrieval from LANDSAT TM 5.” Remote Sensing of environment, 90(4): 434-440. doi:10.1016/j.rse.2004.02.003

Stimson, H.C., D.D., Breshears, S.L., Ustin and S.C., Kefauver. 2005. "Spectral sensing of foliar water conditions in two co-occurring conifer species: Pinus edulis and Juniperus monosperma.” Remote Sensing of Environment, 96(1): 108-118. doi:10.1016/j.rse.2004.12.007

Tang B.-H., Y. Bi, Z.-L. Li* and J. Xia. 2008. "Generalized split-window algorithm for estimate of land surface temperature from Chinese geostationary FengYun meteorological satellite (FY-2C) data." Sensors, 8(65): 933-951. doi:10.3390/s8020933

Tardieu, F. and W.J., Davies. 1992. "Stomatal response to abscisic acid is a function of current plant water status." Plant physiology 98(2): 540-545. doi:10.1104/pp.98.2.540

Testi, L., D.A., Goldhamer, F. Iniesta and M., Salinas. 2008. “Crop water stress index is a sensitive water stress indicator in pistachio trees." Irrigation Science 26(5): 395405. doi:10.1007/s00271-008-0104-5

Tezara, W., V.J., Mitchell, S.D., Driscoll and D.W., Lawlor. 1999. "Water stress inhibits plant photosynthesis by decreasing coupling factor and ATP." Nature 401(6756): 914-917. doi:10.1038/44842 
Turner, N.C., 1981. "Techniques and experimental approaches for the measurement of plant water status." Plant and soil 58(1): 339-366. doi:10.1007/BF02180062

Turner, N.C., 1988. "Measurement of plant water status by the pressure chamber technique.” Irrigation science 9(4):289-308. doi:10.1007/BF00296704

Ullah, S., M., Schlerf, A.K., Skidmore, and C., Hecker. 2012. "Identifying plant species using mid-wave infrared $(2.5-6 \mu \mathrm{m})$ and thermal infrared $(8-14 \mu \mathrm{m})$ emissivity spectra." Remote Sensing of Environment 118:95-102. doi:10.1016/j.rse.2011.11.008

Wan Z. and Z.-L. Li. 2008. "Radiance-based validation of the V5 MODIS land-surface temperature product." International Journal of Remote Sensing, 29(17): 5373-5395. doi: $10.1080 / 01431160802036565$

Yamasaki, S. and L.R., Dillenburg. 1999. "Measurements of leaf relative water content in Araucaria angustifolia." Revista Brasilleira de fisiologia vegetal 11(2), pp.69-75.

Yazar, A., T.A., Howell, D.A., Dusek and K.S., Copeland. 1999. "Evaluation of crop water stress index for LEPA irrigated corn.” Irrigation Science, 18(4):171-180. doi:10.1007/s002710050059

Yuan, G., Y., Luo, X., Sun, and D., Tang. 2004. "Evaluation of a crop water stress index for detecting water stress in winter wheat in the North China Plain.” Agricultural Water Management 64(1):29-40. doi:10.1016/S0378-3774(03)00193-8

Zhang, J. and W.J., Davies 1989. "Abscisic acid produced in dehydrating roots may enable the plant to measure the water status of the soil." Plant, Cell \& Environment 12(1):73-81. doi:10.1111/j.1365-3040.1989.tb01918.x 